\title{
The Correlation of Pulse Wave Velocity and Atherosclerotic Risk Factor in Stroke Patients
}

\author{
Bok Hee Jin ${ }^{1}$ and Min Ho Han ${ }^{2}$ \\ ${ }^{1}$ Department of Clinical Laboratory Science, Wonkwang Health Science University, Iksan 570-750, Korea \\ ${ }^{2}$ Department of Neurology, Yonsei University Severance Hospital, Seoul 120-752, Korea
}

\begin{abstract}
Pulse wave velocity (PWV) is used to non-invasively estimate the severity of arteriosclerosis by measuring arterial stiffness. Increased arterial stiffness measured by PWV stands for progressive arteriosclerosis and is caused by atherosclerotic risk factors. This study is focused on how brachial-ankle pulse wave velocity (baPWV) is related to the leading risk factors for arteriosclerosis or atherosclerosis. Subjects were 114, 69 males and 45 females who are in 60's and had baPWV test for acute stroke. The results are as follows: the group with increased arterial stiffness showed significant increase in $\mathrm{HbA1c}$, total cholesterol, BSBP (brachial artery systolic blood pressure), BDBP (brachial artery diastolic blood pressure), CSBP (central artery systolic blood pressure), CDBP (central artery diastolic blood pressure), augmentation index (Alx) and diabetes mellitus. Correlation analysis between baPWV and atherosclerotic risk factor showed significant relationship in age, HbA1c, LDL cholesterol, BSBP, BDBP, CSBP, CDBP and augmentation index. baPWV was independently related to age and BSBP in multiple linear regression analysis. The group with increased arterial stiffness was independently related to BDBP in multiple logistic regression analysis. This study might be meaningful in evaluating the relationship between arterial stiffness and atherosclerotic risk factor in a new way, and be helped to make various studies for cardiovascular disease.
\end{abstract}

Keywords: Pulse wave velocity, Arterial stiffness, Atherosclerotic risk factor, Stroke

This is an Open Access article distributed under the terms of the Creative Commons Attribution Non-Commercial License (http://creativecommons.org/licenses/by-nc/3.0) which permits unrestricted non-commercial use, distribution, and reproduction in any medium, provided the original work is properly cited.

Copyright @ 2015 The Korean Society for Clinical Laboratory Science. All rights reserved.
Corresponding author: Min Ho Han Department of Neurology, Yonsei University Severance Hospital, Seoul 120-752, Korea Tel: 82-2-2228-5283

E-mail: umsthol18@gmail.com

Received: February 27, 2015

Revised: March 17, 2015

Accepted: March 18, 2015

\section{서 론}

맥파전파속도(pulse wave velocity, 이하 PWV)는 동맥경화증 의 진행 정도와 심혈관계 질환의 위험도를 평가하는데 이용되는 비 침습적인 검사 방법이다(Izzo, 2004). 동맥경화증에 의해 동맥의 탄성도가 감소하여 동맥벽이 단단해지면 동맥의 경직도가 증가되 어 PWV와 맥압(pulse pressure)을 증가시킨다. 따라서 PWV가 증 가한 경우 해당 연령보다 동맥경직도(arterial stiffness)가 증가되 었음을 나타내며, 이렇게 증가된 동맥경직도는 관상동맥질환의 발 생과 밀접한 연관이 있기 때문에(McLeod 등 2004; Boutouyrie 등, 2002) PWV를 측정하여 관상동맥질환의 정도와 뇌혈관 질환과 의 관련성을 파악할 수 있다(Laurent 등, 2003). 또한 동맥경화에 의한 혈관사고(vascular event)의 위험도를 평가하는데 중요한 예 측인자로도 알려져 있다(Blacher 등 1999). 뇌졸중 환자에서도 동
맥경직도의 증가가 뇌졸중의 예후에 영향을 미치는 것으로 알려져 있어 이에 대한 연구가 활발히 진행되고 있다(Choi 등, 2009). Park 등(2005)은 60세 이상의 연령, 당뇨, 고지혈증에서 PWV를 증가시 키는 동맥경직도의 증가는 관상동맥질환을 증가시키는 유의한 위 험인자라고 하였으며, Koji 등(2004)은 PWV의 증가는 심혈관계 질환 사망률의 독립적인 위험인자라고 보고하였다.

대동맥 PWV의 증가에 의한 동맥경직도의 증가는 노화에 따른 혈관의 변화를 나타냄으로서 심혈관계 위험도를 예측하는 유용한 지표로 알려져 있다. 이에 본 연구에서는 위팔-발목 맥파전파속도 (brachial-ankle pulse wave velocity, 이하 baPWV)를 측정하여 동맥경직도와 지금까지 알려져 있는 동맥경화 위험인자와의 관련 성에 대해 알아보고자 하였고, 나아가 새로운 방식을 도입하여 높 은 동맥경직도와 동맥경화 위험인자 및 동맥경화 관련 질환의 유병 률 간의 관련성에 대해 분석하였다. 


\section{재료 및 방법}

\section{1. 대상}

본 연구는 후향성 단면 연구로서 2012년 6월부터 2013년 3월까 지 급성 허혈성 뇌경색(acute ischemic brain infarction)이나 일 과성 허혈 발작(transient ischemic attack)이 발생하여 증상 발현 후 7일 이내에 A병원에 입원한 환자를 대상으로 하였으며 총 114 명(남자 69명, 여자는 45명)이 연구에 참여하였다. 모든 대상자는 병력 및 흡연력을 조사하였으며, 혈액검사와 함께 $\mathrm{baPWV}$ 를 측정 하였다. baPWV 측정 시 불규칙한 맥파로 인해 검사 측정이 어렵고 측정되어도 검사 결과가 부정확할 우려가 있는 부정맥(arrhythmia) 있는 환자(Kim 등, 2011) 또는 말초혈관의 심한 폐색으로 인해 동 맥의 경직도와 상관없이 다양한 속도의 혈류를 야기함으로서 검사 결과의 신뢰성을 떨어뜨릴 우려가 있는 말초폐쇄성동맥질환 (peripheral arterial occlusive disease, PAOD) 및 0.9 미만의 발 목-위팔 동맥압지수(ankle-brachial index, $\mathrm{ABI}$ 를 보이는 환자 는 대상자 선정에서 제외하였다(Motobe 등, 2005). 본 연구는 연 세의료원 세브란스병원 연구심의위원회의 심의를 거쳐 승인을 받 아 진행되었다.

\section{2. 위팔-발목 맥파전파속도(baPWV)의 측정}

모든 대상자는 누운 자세에서 최소 5 분 정도 안정시킨 후 자동파 형분석기(VP-1000, Colin Co, Komaki, Japan)를 사용하여 $\mathrm{baPWV}$ 를 측정하였다. baPWV는 자동파형분석기의 oscillometric sensor가 장착된 4개의 cuff를 양쪽 위팔동맥과 뒤정강동맥에 감 고 동시에 사지의 혈압과 맥파를 기록하였다. 양쪽 손목에 심전도 전극을 부착하여 심장 박동을 감시하였고, 복장뼈 좌측가장자리의 제2갈비사이에 심음도 microphone을 부착하였다. PWV를 결정 하는데 필요한 시간간격 $(\triangle \mathrm{T})$ 은 오른쪽 팔과 양쪽 다리에서 기록된 맥파를 통해 얻어지게 되며, 측정 지점 간의 거리 $(\mathrm{L})$ 는 환자의 신장 을 이용하여 모두 파형분석기에서 자동적으로 계산되었다. 각 편측 의 baPWV는 시간간격 $(\triangle \mathrm{T})$ 을 측정 지점 간의 거리 $(\mathrm{L})$ 로 나누어 얻 을 수 있고, 본 연구에 이용된 baPWV는 양측 $\mathrm{baPWV}$ 의 수치를 평 균화하여 얻어진 값이다. 또한 동맥경직도와 다양한 동맥경화 위험 인자들 간의 상관관계를 파악하기 위해서 baPWV뿐만 아니라 $\mathrm{baPWV}$ 를 통해 얻어진 동맥경직도를 바탕으로 대상자의 $\mathrm{baPWV}$ 가 연령에 비해 낮으면(within normal) 정상군으로, 약간 높거나 (slightly hard), 많이 높으면(harder) 비정상군으로 분류하였다. 이러한 두 군의 세밀한 판단 기준은 결과지의 X축을 연령(year), $\mathrm{Y}$ 축을 $\mathrm{baPWV}(\mathrm{cm} / \mathrm{sec})$ 로 하는 그래프에서 정상범위 안에 대상자 의 baPWV값이 위치할 경우에는 정상군(normal group or with in normal)으로 정의되며, 그 외의 양측 baPWV값 중 어느 한쪽이라 도 정상범위를 상향하여 벗어날 경우에는 비정상군(abnormal group or slightly hard+harder)으로 정의된다.

\section{3. 동맥경화 위험인자}

당뇨는 공복혈당(blood sugar)이 $\geq 7.0 \mathrm{mmol} / \mathrm{L}$ 또는 약이나 인 슐린 치료를 받고 있는 경우이다(Expert Committee on the Diagnosis and Classification of Diabetes Mellitus, 2003). 고콜 레스테롤혈증은 고콜레스테롤혈증을 진단받았거나, 저밀도지단 백콜레스테롤(LDL cholesterol)이 $\geq 4.1 \mathrm{mmol} / \mathrm{L}$ 또는 총콜레스 테롤(total cholesterol)이 $\geq 6.2 \mathrm{mmol} / \mathrm{L}$ 인 경우이다(Expert Panel on Detection, Evaluation, and Treatment of High Blood Cholesterol in Adults, 2001). 고혈압은 진단받았거나, 안정 시 반 복 측정에서 위팔동맥의 수축기혈압(brachial artery systolic blood pressure, 이하 $\mathrm{BSBP}$ )이 $\geq 140 \mathrm{mmHg}$ 또는 이완기혈압 (brachial artery diastolic blood pressure, 이하 BDBP)이 $\geq 90$ $\mathrm{mmHg}$ 인 경우이다(Jones 등, 2004). 현재 흡연은 입원 전까지 흡 연을 하고 있는 경우이다. 체질량지수(body mass index, 이하 $\mathrm{BMI}$ )는 $\mathrm{kg}$ 단위의 몸무게를 $\mathrm{m}$ 단위의 신장의 제곱으로 나누어 산출 하였다. 심장동맥질환은 불안정 협심증이나 심장동맥 폐쇄성 질환 또는 심근경색이 있는 경우이다. $\mathrm{BSBP}$ 와 $\mathrm{BDBP}$ 는 $\mathrm{baPWV}$ 측정 전 누운 자세에서 최소 5 분 정도 안정을 취한 상태로 자동전자혈압계 (OMRON HEM-7220, Omron Healthcare, Japan)를 이용하여 측정된 혈압이다. 중심동맥의 수축기혈압(central artery systolic blood pressure, 이하 CSBP)과 이완기혈압(central artery diastolic blood pressure, 이하 CDBP)은 자동파형분석기(SphygmoCor, AtCor Medical, NSW, Australia)를 통해 측정된 노동맥(radial artery) 파형을 일반적인 전달 공식(generalized transfer function) 에 적용하여 측정된 혈압이다. 허리둘레(waist circumference)는 바로 누운 자세에서 배꼽부위를 줄자로 측정하였다.

\section{4. 통계분석}

대상자의 임상 특성은 기술통계분석을 통해 얻어진 연속형 변수 에 대해서는 평균士표준편차로 표현하였으며, 범주형 변수에 대해 서는 관측빈도(\%)로 기술하였다. $\mathrm{baPWV}$ 결과에 따른 정상군과 비 정상군 간의 동맥경화 위험인자의 통계적 차이를 확인하기 위해서 독립 T검정(independent T-test) 분석을 실시하였다. 또한 두 군 간의 동맥경화 관련 질환의 유병률을 비교하기 위해서 교차분석을 실시하였으며, 단 분할표에서 cell의 기대빈도가 5 이하인 경우가 전체 20\%를 넘는 경우에는 Fisher's exact test를 실시하여 얻어진 $p$ value를 사용하였다. 동맥경화 위험인자와 $\mathrm{baPWV}$ 간의 상관관 
Table 1. Comparison of atherosclerotic risk factors according to arterial stiffness

\begin{tabular}{|c|c|c|c|}
\hline Variables & $\begin{array}{l}\text { Normal group (within normal) } \\
\qquad \mathrm{N}=13\end{array}$ & $\begin{array}{l}\text { Abnormal group (slightly hard+harder) } \\
\qquad \mathrm{N}=101\end{array}$ & $p$ value \\
\hline Male (\%) & $10(76.9)$ & $59(58.4)$ & 0.199 \\
\hline Age (year) & $63.85 \pm 10.61$ & $61.81 \pm 11.10$ & 0.533 \\
\hline BMI $\left(\mathrm{kg} / \mathrm{m}^{2}\right)$ & $23.88 \pm 2.23$ & $24.04 \pm 3.16$ & 0.861 \\
\hline Waste circumference $(\mathrm{cm})$ & $84.50 \pm 8.17$ & $86.78 \pm 8.76$ & 0.393 \\
\hline Blood sugar (mg/dL) & $133.77 \pm 30.32$ & $145.78 \pm 60.73$ & 0.485 \\
\hline $\mathrm{HbAlc}(\mathrm{mg} / \mathrm{dL})$ & $6.18 \pm 0.46$ & $6.61 \pm 1.24$ & 0.032 \\
\hline Total cholesterol (mg/dL) & $154.49 \pm 61.48$ & $179.30 \pm 38.69$ & 0.046 \\
\hline Triglyceride $(\mathrm{mg} / \mathrm{dL})$ & $108.45 \pm 54.68$ & $133.11 \pm 80.21$ & 0.323 \\
\hline HDL cholesterol (mg/dL) & $41.83 \pm 6.85$ & $43.53 \pm 13.21$ & 0.662 \\
\hline LDL cholesterol (mg/dL) & $100.58 \pm 29.69$ & $100.78 \pm 31.74$ & 0.984 \\
\hline $\mathrm{BSBP}(\mathrm{mmHg})$ & $127.77 \pm 18.80$ & $142.03 \pm 20.82$ & 0.021 \\
\hline BDBP (mmHg) & $71.85 \pm 8.68$ & $83.43 \pm 11.84$ & 0.001 \\
\hline CSBP (mmHg) & $114.46 \pm 18.32$ & $130.63 \pm 19.98$ & 0.007 \\
\hline $\mathrm{CDBP}(\mathrm{mmHg})$ & $72.77 \pm 8.67$ & $84.59 \pm 12.02$ & 0.001 \\
\hline Augmentation index (Alx) & $19.46 \pm 9.62$ & $25.11 \pm 9.41$ & 0.044 \\
\hline baPWV $(\mathrm{cm} / \mathrm{sec})$ & $1460.42 \pm 187.26$ & $1976.63 \pm 481.81$ & $<0.001$ \\
\hline Diabetes mellitus (\%) & $1(7.7)$ & $41(40.6)$ & 0.029 \\
\hline Hypercholesterolemia (\%) & $1(7.7)$ & $16(15.8)$ & 0.688 \\
\hline Hypertension (\%) & $6(46.2)$ & $66(65.3)$ & 0.225 \\
\hline Smoking (\%) & $3(23.1)$ & $25(24.8)$ & 1.000 \\
\hline Coronary artery disease (\%) & $3(23.1)$ & $36(35.6)$ & 0.537 \\
\hline
\end{tabular}

BMI (body mass index)=weight $(\mathrm{kg}) /[\text { height }(\mathrm{m})]^{2}$.

HbAlc, Hemoglobin Alc; BSBP, brachial artery systolic blood pressure; BDBP, brachial artery diastolic blood pressure; CSBP, central artery systolic blood pressure; CDBP, central arthery diastolic blood pressure; baPWV, brachial-ankle pulse wave velocity.

계는 Pearson correlation에 의해 얻어졌다. 단변량 분석을 통해 통계적으로 유의한 차이를 보이는 동맥경화 위험인자들은 혼란변 수를 제거하고도 독립적으로 baPWV에 영향을 미치는지를 파악하 기 위해서 다변량 선형 회귀분석을 실시하였다. 비정상군과 동맥경 화 위험인자 간에 독립적으로 유의한 관련성이 있는지 파악하기 위 해서 다변량 로지스틱 회귀분석을 실시하였다.

모든 통계분석은 SPSS Win (ver 18.0)을 이용하여 시행되었으 며, 통계적으로 유의한 수준은 양측 검정에서 $p$ value가 0.05 미만 일 경우이다.

\section{결 과}

\section{1. 동맥경직도에 따른 동맥경화 위험인자의 비교}

뇌졸중으로 입원한 연령층은 주로 60 대였으며, 신장과 체중으 로부터 구한 BMI는 정상에 해당되었다. 모든 대상자는 $\mathrm{baPWV}$ 를 바탕으로 정상군과 비정상군으로 나누어 통계분석을 실시하였다. 성별, 연령, BMI, 허리둘레, 공복혈당, 중성지방(triglyceride), 고 밀도지단백콜레스테롤(HDL cholesterol), 저밀도지단백콜레스 테롤은 두 군 간에 유의미한 차이는 없었다. 당뇨를 제외한 동맥경 화 관련 질환 모두에서 통계적으로 유의미한 차이가 관찰되지 않았 다. 당화혈색소(HbAlc), 총콜레스테롤, 증가지수(augmentation
Table 2. Correlation between brachial-ankle pulse wave velocity and atherosclerotic risk factors

\begin{tabular}{lcr}
\hline \multicolumn{1}{c}{ Variables } & Pearson correlation & $p$ value \\
\hline Age (year) & 0.524 & $<0.001$ \\
BMI (kg/m ${ }^{2}$ ) & -0.092 & 0.329 \\
Waste circumference $(\mathrm{cm})$ & 0.109 & 0.254 \\
Blood sugar $(\mathrm{mg} / \mathrm{dL})$ & 0.181 & 0.054 \\
HbAlc $(\mathrm{mg} / \mathrm{dL})$ & 0.209 & 0.032 \\
Total cholesterol (mg/dL) & -0.159 & 0.091 \\
Triglyceride $(\mathrm{mg} / \mathrm{dL})$ & 0.042 & 0.658 \\
HDL cholesterol $(\mathrm{mg} / \mathrm{dL})$ & -0.008 & 0.930 \\
LDL cholesterol $(\mathrm{mg} / \mathrm{dL})$ & -0.262 & 0.005 \\
BSBP (mmHg) & 0.482 & $<0.001$ \\
BDBP (mmHg) & 0.302 & 0.001 \\
CSBP (mmHg) & 0.443 & $<0.001$ \\
CDBP (mmHg) & 0.306 & 0.001 \\
Augmentation index (Alx) & 0.267 & 0.004 \\
\hline
\end{tabular}

BMI (body mass index)=weight $(\mathrm{kg}) /[\text { height }(\mathrm{m})]^{2}$.

HbAlc, Hemoglobin Alc; BSBP, brachial artery systolic blood pressure; BDBP, brachial artery diastolic blood pressure; CSBP, central artery systolic blood pressure; CDBP, central arthery diastolic blood pressure.

index, 이하 AIx), 당뇨는 비정상군에서 유의미하게 증가되었다 $(p<0.05) . \operatorname{BSBP}(p<0.05)$ 와 $\operatorname{BDBP}(p<0.01)$ 는 동맥경직도가 높 은 비정상군에서 유의미하게 증가되었다. 그리고 노동맥으로부터 탐촉자를 이용하여 얻어진 맥파를 통해 혈압을 구하는 CSBP와 
$\mathrm{CDBP}$ 도 동맥경직도가 높은 비정상군에서 유의미하게 증가되었 다 $(p<0.01)$. 또한 $\mathrm{baPWV}$ 도 동맥경직도가 높은 비정상군에서 유 의미하게 증가되었다 $(p<0.001)$ (Table 1).

\section{2. 동맥경화 위험인자와 baPWV 간의 상관관계}

뇌졸중 환자에서 $\mathrm{baPWV}$ 와 동맥경화 위험인자와의 상관관계를 보기 위해 Pearson 상관계수 분석을 실시한 결과 연령 $(p<0.001)$, $\mathrm{HbAlc}(p<0.05)$ 은 유의미한 양의 상관관계를 나타냈다. 또한 $\operatorname{BSBP}(p<0.001)$ 와 $\operatorname{BDBP}(p<0.01), \operatorname{CSBP}(p<0.001)$ 와 $\mathrm{CDBP}$ $(p<0.01)$ 도 유의미한 양의 상관관계를 나타냈다. 저밀도지단백콜 레스테롤 $(p<0.01)$ 은 유의미한 음의 상관관계를 나타냈다. 그러나 $\mathrm{BMI}(p=0.329)$, 허리둘레 $(p=0.254)$, 혈당 $(p=0.054)$, 총콜레스테롤 $(p=0.091)$, 중성지방 $(p=0.658)$, 고밀도지단백콜레스테롤 $(p=0.930)$ 은 통계적으로 유의미한 상관관계를 나타내지 않았다(Table 2).

\section{3. 동맥경화 위험인자와 $\mathrm{baPWV}$ 의 관계}

단변량 선형 회귀분석에서 $\mathrm{baPWV}$ 와 통계적으로 유의미한 선형 관계를 보이는 변수로는 연령 $(p<0.001), \mathrm{HbAlc}(p<0.05)$, 저밀도 지단백콜레스테롤 $(p<0.01), \mathrm{BSBP}(p<0.001), \mathrm{BDBP}(p<0.01)$, $\operatorname{AIx}(p<0.01)$ 가 있었다. 다음의 변수들 중 다변량 선형 회귀분석 을 통해 혼란변수를 제외하고 독립적으로 $\mathrm{baPWV}$ 와 유의미한 선 형관계를 보이는 변수는 연령 $(p<0.001)$ 과 $\operatorname{BSBP}(p<0.05)$ 로 한 정되었다(Table 3).

\section{4. 동맥경화 위험인자와 동맥경직도의 관계}

비정상군을 종속변수로 하는 단변량 로지스틱 회귀분석에서 $\operatorname{BSBP}(p<0.05), \operatorname{BDBP}(p<0.01)$, 당뇨 $(p<0.05)$ 는 통계적으로 유의미한 양의 상관관계를 보였다. 하지만 다변량 로지스틱 회귀분 석에서 독립적으로 유의미한 양의 관계를 보이는 동맥경화 위험인 자는 $\mathrm{BDBP}$ 뿐이었다 $(p<0.05)$ (Table 4).

Table 3. Association between brachial-ankle pulse wave velocity and atherosclerotic risk factors

\begin{tabular}{|c|c|c|c|c|}
\hline \multirow{2}{*}{ Variables } & \multicolumn{2}{|c|}{ Univariate } & \multicolumn{2}{|c|}{ Multivariate } \\
\hline & B & $p$ value & B & $p$ value \\
\hline Age (year) & 23.129 & $<0.001$ & 26.271 & $<0.001$ \\
\hline BMI $\left(\mathrm{kg} / \mathrm{m}^{2}\right)$ & -14.665 & 0.329 & -20.517 & 0.253 \\
\hline Waste circumference $(\mathrm{cm})$ & 6.113 & 0.254 & 2.046 & 0.751 \\
\hline Blood sugar (mg/dL) & 1.513 & 0.054 & 0.115 & 0.869 \\
\hline $\mathrm{HbAlc}$ (mg/dL) & 87.423 & 0.032 & 55.949 & 0.167 \\
\hline Total cholesterol (mg/dL) & -1.830 & 0.091 & -0.548 & 0.657 \\
\hline Triglyceride $(\mathrm{mg} / \mathrm{dL})$ & 0.263 & 0.658 & -0.262 & 0.564 \\
\hline HDL cholesterol (mg/dL) & -0.321 & 0.930 & 3.134 & 0.265 \\
\hline LDL cholesterol (mg/dL) & -4.047 & 0.005 & -1.338 & 0.404 \\
\hline $\mathrm{BSBP}(\mathrm{mmHg})$ & 11.141 & $<0.001$ & 6.964 & 0.037 \\
\hline $\mathrm{BDBP}(\mathrm{mmHg})$ & 12.173 & 0.001 & 10.617 & 0.069 \\
\hline Augmentation index (Alx) & 13.594 & 0.004 & 1.317 & 0.731 \\
\hline
\end{tabular}

BMI (body mass index)=weight $(\mathrm{kg}) /[\text { height }(\mathrm{m})]^{2}$.

HbAlc, Hemoglobin Alc; BSBP, brachial artery systolic blood pressure; BDBP, brachial artery diastolic blood pressure; baPWV, brachial-ankle pulse wave velocity.

Table 4. Association between arterial stiffness and atherosclerotic risk factors

\begin{tabular}{|c|c|c|c|c|c|c|}
\hline \multirow{2}{*}{ Variables } & \multicolumn{3}{|c|}{ Univariate } & \multicolumn{3}{|c|}{ Multivariate } \\
\hline & Odds ratio & Standard error & $p$ value & Odds ratio & Standard error & $p$ value \\
\hline $\mathrm{HbAlc}(\mathrm{mg} / \mathrm{dL})$ & 1.565 & 0.404 & 0.268 & 0.823 & 0.614 & 0.751 \\
\hline Total cholesterol (mg/dL) & 1.013 & 0.007 & 0.054 & 1.016 & 0.008 & 0.058 \\
\hline $\mathrm{BSBP}(\mathrm{mmHg})$ & 1.039 & 0.017 & 0.024 & 0.967 & 0.036 & 0.345 \\
\hline $\mathrm{BDBP}(\mathrm{mmHg})$ & 1.111 & 0.034 & 0.002 & 1.159 & 0.066 & 0.025 \\
\hline Augmentation index (Alx) & 1.060 & 0.030 & 0.05 & 1.052 & 0.044 & 0.243 \\
\hline Diabetes mellitus (\%) & 8.200 & 1.060 & 0.047 & 13.018 & 1.595 & 0.108 \\
\hline
\end{tabular}

BMI (body mass index)=weight $(\mathrm{kg}) /[\text { height }(\mathrm{m})]^{2}$.

HbAlc, Hemoglobin Alc; BSBP, brachial artery systolic blood pressure; BDBP, brachial artery diastolic blood pressure; baPWV, brachial-ankle pulse wave velocity. 


\section{고 찰}

동맥의 PWV는 심혈관계 질환의 증상이 발생하기 전에 동맥의 변화를 초기에 진단하기 위한 검사로서 임상에서 많이 측정되고 있 다. 또한 동맥의 경직도가 증가할수록 PWV는 증가되며 많은 심혈 관계 질환의 위험인자와 관계가 있다는 것은 이미 잘 알려져 있다 (Zo 등, 2006).

정상인에서도 심혈관계 질환에 의한 사망률의 증가는 성별과 관 련되어 있고(Sutton-Tyrrell 등, 2005), 또한 London 등(1995)은 $\mathrm{PWV}$ 가 젊은이에서는 남자가 여자보다 감소한다고 하였으며, Amar 등(2001)은 성별이 PWV의 증가와 유의미한 상관관계가 있 다고 보고하였다. 그러나 본 연구에서는 대상자가 뇌졸중이 발생하 여 입원한 고연령층이 대부분이기 때문에 상대적으로 나이가 어린 대상자에서 보였던 성별의 차이는 관찰하기 어렵고, 기존 연구에서 연속형 변수인 PWV가 성별에 따라 통계적으로 유의미한 차이가 있었다 할지라도, 본 연구에서는 자동파형분석기에서 성별에 대한 차이를 고려한 정상 참고치를 바탕으로 제시된 결과를 정상군과 비 정상군으로 나누어 통계분석을 실시하였기 때문에 성별에 대한 동 맥경직도가 보정될 수 있어서 PWV에 영향을 미치는 인자 중 하나 인 성별에 대하여 통계적으로 유의미한 차이를 관찰할 수 없었던 것으로 생각된다. 한편 Park 등(2005)이 보고한 성별은 대동맥 PWV에 영향을 주지 않는다는 연구 결과는 본 연구 결과와 일치하 는 소견을 보였다.

$\mathrm{PWV}$ 는 혈압이나 다른 위험인자의 존재와 관계없이 연령이 증 가할수록 증가한다(Relf 등, 1986; Amar 등, 2001). Park 등(2005) 도 연령이 증가하는 경우 대동맥 PWV는 통계적으로 유의하게 증 가되며, 연령을 연속변수로 하여 분석하였을 때에도 연령은 대동맥 경직도의 증가와 유의미한 상관관계가 있다고 하였다. 또한 60 세 이상에서 대동맥 PWV의 증가는 독립적 위험인자였다고 보고하였 다. 즉 연령이 PWV의 증가와 독립적으로 유의한 상관관계가 있다 고 보고한 기존 연구들은 본 연구에서 제시된 Table 2 와 3 의 결과와 일치하였다. 한편 London 등(1995)은 고연령군에서는 모든 부위 에서 측정한 PWV가 차이가 없었다고 보고하였다. 이와 같은 것은 Table 1에서 연령에 대하여 동맥경직도에 따른 두 군 간에 통계적 으로 유의미한 차이를 보이지 않았던 본 연구 결과와 일부 일치하 는 소견이다. 보통 연령의 증가에 의한 동맥경직도의 증가는 고연 령군에서 약간의 차이를 보일지라도 둘은 독립적으로 유의미한 양 의 상관관계를 가진다고 할 수 있다. 또한 동맥의 부위에 따라 둘의 상관관계는 약간의 차이를 보일 수 있으며, 말초동맥보다는 주로 중심동맥의 경직도가 연령에 따라서 분명하게 증가한다.

비만이 있는 경우 대동맥 PWV는 유의미하게 증가되었다고 보
고하였다(Park 등(2005). 그러나 본 연구에서는 주로 60세 이상의 대상자로서 비만인 사람이 거의 없었기 때문에 유의미한 차이는 관 찰할 수 없었다.

고혈압 등에 의해서 동맥이 경화되면 동맥경직도의 증가에 의해 수축기혈압은 증가시키고, 이완기 혈압은 감소시켜 줌으로서 맥압 (pulse pressure)을 증가시키게 된다(Hamilton 등, 2011; Zieman 등 2005). 따라서 심장에서는 후부하(afterload)가 증가함에 따라 좌심실비대가 발생하며 (Girerd 등, 1991), 이완기에는 관상동맥의 혈류가 감소하는 허혈이 발생하므로 관상동맥질환의 발생 위험이 증가하게 되어(Franklin 등, 1999) 결과적으로는 전체 심혈관계 질 환의 위험도를 증가시키게 된다. 따라서 대동맥 PWV는 고혈압이 있는 경우 매우 유의미하게 증가되었으며(Park 등, 2005), Amar 등(2001)은 PWV를 비침습적으로 측정한 결과 수축기혈압이 $\mathrm{PWV}$ 의 증가와 유의미한 상관관계가 있었다고 보고하였다. 이와 같은 것은 본 연구에서 동맥경직도가 높은 군에서 혈압이 유의미하 게 증가된 결과와 일치하였다. 고혈압 여부 대신에 대동맥 내에 거 치한 심도자를 이용하여 맥파와 동시에 기록된 혈압을 이용한 다변 량분석에서 대동맥 내의 수축기혈압이나 평균혈압을 이용한 경우 두 가지 모두 대동맥 PWV 증가의 강력한 독립적인 위험인자였다 (Park 등, 2005). 이러한 연구 결과는 본 연구에서도 마찬가지로 동 맥경직도가 높은 비정상군에서 자동파형분석기를 통해 얻어진 $\mathrm{CSBP}$ 와 $\mathrm{CDBP}$ 가 모두 높게 나온 것과 일치하는 소견이다. 또한 두 중심혈압은 baPWV와도 높은 상관관계를 보였으나 고혈압 유병률 은 비정상군에서 통계적으로 유의미한 증가를 관찰할 수 없었다. 즉 본 연구를 통해 $\mathrm{baPWV}$ 로부터 예측된 동맥경직도는 고혈압 유 병률보다는 측정 당시의 수축기혈압이나 이완기혈압에 의해 상승 될 수 있음을 알 수 있었다.

당뇨가 있는 경우 60 세 이상의 연령에서 PWV가 증가한다고 보 고되었다(Park 등, 2005). 이러한 결과는 본 연구와 동일한 대상으 로 연구되었던 저자의 선행연구의 내용과 일치하는 소견이다(Jin 등, 2014). 그러나 이번 연구에서는 새로운 변수가 일부 추가되고, 다변량 회귀분석을 통해 혼란변수들을 배제하여 동맥경직도가 높 은 비정상군과 당뇨 유병률 간의 독립적인 상관관계를 파악하였다. 그 결과 비정상군에서 당뇨의 유병률은 독립적으로 유의미한 증가 를 보이지는 않았다. 고콜레스테롤혈증, 심장동맥질환, 흡연은 저 자의 선행연구의 내용과 마찬가지로 다변량 회귀분석에서 통계적 으로 유의미한 차이는 관찰되지 않았다.

본 연구에서는 뇌졸중 환자를 대상으로 기존에 많이 연구되었던 $\mathrm{PWV}$ 와 동맥경화 위험인자와의 상관관계를 알아보고, 더 나아가 $\mathrm{baPWV}$ 장비에서 제공되는 동맥경직도의 소견을 바탕으로 대상자 를 두 군으로 나누어 위험인자와의 관계를 다변량 로지스틱 회귀분 
석을 통해 독립적으로 유의미한 위험인자를 새롭게 파악하고자 노 력하였다. 따라서 연속형 변수인 baPWV와 위험인자 간의 상관관 계는 기존 연구들과 마찬가지로 연령과 $\mathrm{BSBP}$ 가 독립적인 위험인 자였다. 반면 비정상군과 위험인자 간의 다변량로지스틱 회귀분석 에서는 $\mathrm{BDBP}$ 가 유일하게 독립적인 위험인자로 관찰되어 기존 연 구와는 조금 다른 의미를 가질 수 있었다.

본 연구에서 몇 가지 한계점을 개선한다면 결과의 신빙성을 높 이는데 큰 도움이 될 것으로 생각된다. 첫째, PWV를 이용한 기존 연구들에서는 대상자의 수가 최소 500 명 이상이었던 반면, 본 연구 의 대상자는 상대적으로 작은 규모로 시행되어 결과의 신빙성이 떨 어질 우려가 있다. 둘째, 본 연구는 기존 연구방식 뿐만 아니라 대상 자의 baPWV 결과를 바탕으로 두 군으로 나누어 새롭게 추가하여 진행하였다. 하지만 기존 선행 연구자들은 본 연구에서 사용된 새 로운 방식으로 대상자를 나누어 연구를 진행한 적이 없었기 때문 에, 앞으로 보다 더 많은 연구를 통해 본 연구의 방식이 입증될 필요 가 있으며, 그러한 연구들은 본 연구 결과의 신빙성을 높이고, 앞으 로 다양한 연구를 진행하는데 큰 도움이 될 것으로 생각된다. 이러 한 한계점에도 불구하고, 본 연구는 기존의 접근 방식과 더불어 새 로운 접근 방식을 도입하여 서로 비교하고 연구 방법을 다양하게 시도했다는 점에서 의미를 가질 수 있다.

Acknowledgements: 본 연구는 2014학년도 원광보건대학교 교 내연구비에 의해 연구되었으며 이에 감사드립니다.

Funding: 원광보건대학교 교내연구비

Conflict of interest: None

\section{References}

1. Amar J, Ruidavets JB, Chamontin B, Drouet L, Ferrieres J. Arterial stiffness and cardiovascular risk factors in a population based study. J Hypertens. 2001, 19:381-387.

2. Blacher J, Asmar R, Djane S, London GM, safar ME. Aortic pulse wave velocity as a marker of cardiovascular risk in hypertensive patients. Hypertension. 1999, 33:1111-1117.

3. Boutouyrie P, Tropeano AI, Aamar R, Gautier I, Benetos A, Lacolley P, et al. Aortic stiffness is an independent predictor of primary coronary events in hypertensive patients: A longitudinal study. Hypertension. 2002, 39:10-15.

4. Choi JC, Lee JS, Kang SY, Kang JH, Bae JM, Lee DH. Limitation of brachial-ankle pulse wave velocity in assessing the risk of stroke: Importance of instantaneous blood pressure. Cerebrovasc Dis. 2009, 27:417-425.

5. Expert Committee on the Diagnosis and Classification of Diabetes Mellitus. Report of the expert committee on the diagnosis and classification of diabetes mellitus. Diabetes Care. 2003, 26Suppl1:S5-20.
6. Expert Panel on Detection, Evaluation, and Treatment of High Blood Cholesterol in Adults. Executive Summary of The Third Report of The National Cholesterol Education Program (NCEP) Expert Panel on Detection, Evaluation, And Treatment of High Blood Cholesterol In Adults (Adult Treatment Panel III). JAMA. 2001, 285(19):2486-2497.

7. Franklin SS, Khan SA, Wong ND, Larson MG, Levy D. Is pulse pressure useful in predicting risk for coronary heart disease? The Framingham Heart Study. Circulation. 1999, 100:354-360.

8. Girerd X, Laurent S, Pannier B, Asmar R, Safar M. Arterial distensibility and left ventricular hypertrophy in patients with sustained essential hypertension. Am Heart J. 1991, 122:1210-1214.

9. Hamilton PK, Lockhart CJ, Quinn CE, McVeigh GE. Arterial stiffness: Clinical relevance, measurement and treatment. Clin SCi(Lond). 2011, 100:387-393.

10. Izzo JL. Arterial stiffness and the systolic hypertension syndrome. Curr Opin Cardiol. 2004, 19:341-352.

11. Jin BH, Han MH. Comparion of Clinical Laboratory Data and Prevalence according to Arterial Stiffness in Stroke Patients. Korean J Clin Lab Sci. 2014, 46(4):143-149.

12. Jones DW, Hall JE. Seventh report of the Joint National Committee on Prevention, Detection, Evaluation, and Treatment of High Blood Pressure and evidence from new hypertension trials. Hypertension. 2004, 43(1):1-3.

13. Kim J, Cha MJ, Lee DH, Lee HS, Nam CM, Nam HS, et al. The association between cerebral atherosclerosis and arterial stiffness in acute ischemic stroke. Atherosclerosis 2011, 219(2):887-891.

14. Koji Y, Tomiyama H, Ichihashi H, Nagae T, Tanaka N, Takazawa $\mathrm{K}$, et al. Comparison of ankle-brachial pressure index and pulse wave velocity as markers of the presence of coronary artery disease in subjects with a high risk of atherosclerotic cardiovascular disease. Am J Cardiol. 2004, 94:868-872.

15. Laurent S, Katsahian S, Fassot C, Tropeano AI, Gautier I, Laloux $\mathrm{B}$, et al. Aortic stiffness is an independent predictor of fatal stroke in essential hypertension. Sroke. 2003, 34:1203-1206.

16. London GM, Guerin AP, Pannier B, Marchais SJ, Stimpel M. Influence of sex on arterial hemodynamics and blood pressure: role of body height. Hypertension. 1995, 26:514-519.

17. McLeod AL, Uren NG, Wilkinson IB. Non-invasive measures of pulse wave velocity correlate with coronary arterial plaque load in humans. J Hypertens. 2004, 22:363-368.

18. Motobe K, Tomiyama H, Koji Y, Yambe M, Gulinisa Z, Arai T, et al. Cut-off value of the ankle-brachial pressure index at which the accuracy of brachial-ankle pulse wave velocity measurement is diminished. Circulation Journal : official journal of the Japanese Circulation Society. 2005, 69(1):55-60.

19. Park JS, Seo JJ, Chung JW, Cho HJ, Bae JW, Kim KI, et al. Association of the Invasively Measured Aortic Stiffness and Coronary Artery Disease. Korean Circulation J. 2005, 35:766-772.

20. Relf IR, Lo CS, Myers KA, Wahlqvist ML. Risk factors for changes in aorto-iliac arterial compliance in healthy men. Atherosclerosis. 1986, 6:105-108.

21. Sutton-Tyrrell K, Najjar SS, Boudreau RM, Venkitachalam L, Kupelian V, Simonsick EM, et al. Elevated aortic pulse wave velocity, a marker of arterial stiffness, predicts cardiovascular events in well-functioning older adults. Circulation. 2005, 111: 3384-3390. 
34 Bok Hee Jin and Min Ho Han. The Correlation of Pulse Wave Velocity and Atherosclerotic Risk Factor in Stroke Patients

22. Zieman Sj, Melenovsky V, Kass DA. Mechanisms, pathophysiology, and therapy of arterial stiffness. Arterioscler Thromb Vasc Biol. 2005, 25:932-943.

23. Zo JH, Lee SK, Kim SH, Kim MA. The Relationship of
Pulse-wave Velocity with Carotid Intima-media Thickness and Carotid Artery Distensibility. J Cardiovasc Ultrasound. 2006, 14(3):92-97. 